ఠ

\title{
Appointment reminder systems are effective but not optimal: results of a systematic review and evidence synthesis employing realist principles
}

This article was published in the following Dove Press journal:

Patient Preference and Adherence

4 April 2016

Number of times this article has been viewed

\author{
Sionnadh Mairi McLean' \\ Andrew Booth ${ }^{2}$ \\ Melanie $\mathrm{Gee}^{3}$ \\ Sarah Salway ${ }^{2}$ \\ Mark Cobb ${ }^{4}$ \\ Sadiq Bhanbhro 3 \\ Susan A Nancarrow ${ }^{5}$ \\ 'Faculty of Health and Wellbeing, \\ Sheffield Hallam University, Sheffield, \\ UK; ${ }^{2}$ School of Health and Related \\ Research, University of Sheffield, \\ Sheffield, UK; ${ }^{3}$ Centre for Health \\ and Social Care Research, Sheffield \\ Hallam University, Sheffield, UK; \\ ${ }^{4}$ Therapeutics \& Palliative Care, \\ Sheffield Teaching Hospitals, Sheffield, \\ UK; ${ }^{5}$ School of Health and Human \\ Science, Southern Cross University, \\ East Lismore, NSW, Australia
}

Correspondence: Sionnadh Mairi McLean Collegiate Campus, Sheffield Hallam University, 38 Collegiate Crescent, Sheffield, SIO 2BP, UK

Tel +44 II4 225 227I

Emails.mclean@shu.ac.uk

\begin{abstract}
Missed appointments are an avoidable cost and resource inefficiency which impact upon the health of the patient and treatment outcomes. Health care services are increasingly utilizing reminder systems to manage these negative effects. This study explores the effectiveness of reminder systems for promoting attendance, cancellations, and rescheduling of appointments across all health care settings and for particular patient groups and the contextual factors which indicate that reminders are being employed sub-optimally. We used three inter-related reviews of quantitative and qualitative evidence. Firstly, using pre-existing models and theories, we developed a conceptual framework to inform our understanding of the contexts and mechanisms which influence reminder effectiveness. Secondly, we performed a review following Centre for Reviews and Dissemination guidelines to investigate the effectiveness of different methods of reminding patients to attend health service appointments. Finally, to supplement the effectiveness information, we completed a review informed by realist principles to identify factors likely to influence non-attendance behaviors and the effectiveness of reminders. We found consistent evidence that all types of reminder systems are effective at improving appointment attendance across a range of health care settings and patient populations. Reminder systems may also increase cancellation and rescheduling of unwanted appointments. "Reminder plus", which provides additional information beyond the reminder function may be more effective than simple reminders (ie, date, time, place) at reducing non-attendance at appointments in particular circumstances. We identified six areas of inefficiency which indicate that reminder systems are being used sub-optimally. Unless otherwise indicated, all patients should receive a reminder to facilitate attendance at their health care appointment. The choice of reminder system should be tailored to the individual service. To optimize appointment and reminder systems, health care services need supportive administrative processes to enhance attendance, cancellation, rescheduling, and re-allocation of appointments to other patients.
\end{abstract}

Keywords: attendance, cancellation, rescheduling, TURNUP

\section{Introduction}

Missed health care appointments are a major source of avoidable inefficiency that impacts on patient health and treatment outcomes. Data on non-attendance vary, however studies from around the world consistently report non-attendance rates of between 15\% and 30\% in outpatient health clinics. ${ }^{1-4}$ In England, more than 12 million appointments at consultant led clinics, ${ }^{5}$ and a similar number of general practice appointments are missed each year. ${ }^{6}$ The cost of missed appointments to the UK National Health Service (NHS) has tripled since 1999. ${ }^{7}$ In 2009, non-attendance was estimated to cost over $£ 600$ million (around US\$970 million). ${ }^{8}$ 
The consequences of non-attendance include increased appointment waiting times, ${ }^{9}$ increased costs of care delivery, ${ }^{10,11}$ underutilization of equipment and personnel, ${ }^{10}$ reduced appointment availability, ${ }^{6,11}$ reduced patient satisfaction, ${ }^{12,13}$ and negative relationships between patients and staff. ${ }^{6,9}$ Missed appointments may delay presentation at health services, resulting in a lack of follow-up of chronic conditions which may ultimately lead to complications, unnecessary suffering, and costly hospital admission. ${ }^{10,14}$ Pressures from referring agents to manage waiting lists, can potentially increase staff stress, anxiety, and fatigue levels. ${ }^{15}$ Reducing the number of missed appointments may be a relatively inexpensive way to increase health care efficiency, effectiveness, and quality.

Numerous reviews have demonstrated the effectiveness of existing reminder systems in varied service settings. However, research to-date focusses on the use of reminder systems in particular service contexts or technologies, ${ }^{16-18}$ rather than synthesizing knowledge across different contexts and patient groups. This study explores the effectiveness of reminder systems for promoting attendance, cancellations, and rescheduling of appointments across all health care settings and for particular patient groups and the contextual factors which indicate that reminders are being employed sub-optimally.

\section{Material and methods}

Our project incorporated three components: the development of a conceptual framework to provide an understanding of the contexts and mechanisms which influence reminder effectiveness (review 1); a systematic review (SR) of the reminder effectiveness literature (review 2), and an evidence synthesis informed by realist principles to explain the contexts and mechanisms which influence reminder effectiveness (review 3). We used realist inquiry because it clarifies the context-mechanism-outcome relationships in an attempt to understand better what works, for whom, under what circumstances. ${ }^{19}$ Further detail on the methodology employed is available in the TURNUP project report. ${ }^{20}$

Searches were conducted on 13 databases with date limits of January 1, 2000 to February 15, 2012: AMED, CINAHL Plus with Full Text, Cochrane Library, Embase, HMIC, IEEE Xplore, Kings Fund Library Catalogue, Maternity and Infant Care, MEDLINE, PEDro, PsycINFO, SportDiscus, and Web of Science. The strategy used the concept of (reminders/prompts/alerts) in proximity to (appointments) (Figure 1). Where supported, appropriate database headings/thesaurus terms were used. The reference lists of included randomized controlled trials (RCTs) and SRs were screened for additional relevant studies and citation (forward-) searches were performed in respect of the included RCTs. English-language studies of various quantitative and qualitative designs were included if they investigated the effectiveness of outpatient appointment reminders, appointment attendance behavior, or explicated theories/models/frameworks relating to reminder systems or appointment attendance. Studies were excluded if they investigated reminders sent to a patient inviting them to schedule an appointment. All members of the project team were involved in screening and selection of studies and data extraction from included studies.

\section{Review I}

We could find few pre-existing conceptual models or frameworks that directly explain the mechanisms by which

\begin{tabular}{|ll|}
\hline & Citations \\
S1 (MH "Reminder Systems") & 2,850 \\
S2 TI reminder* OR AB reminder* & 8,104 \\
S3 TI appointment* OR AB appointment* & 18,257 \\
S4 (MH "Appointments and Schedules") & 10,007 \\
S5 s3 OR s4 & 25,901 \\
S6 s5 AND s1 & 409 \\
S7 s1 OR s2 & 9,797 \\
S8 s7 AND s4 & 452 \\
S9 s6 OR s8 & 543 \\
S10 TI remind* n5 appointment* OR AB remind* n5 appointment* & 277 \\
S11 TI prompt* n5 appointment* OR AB prompt* n5 appointment & 34 \\
S12 TI alert* n5 appointment* OR AB alert* n5 appointment & \\
S13 S10 OR S11 OR S12 & 6 \\
S14 S9 OR S13 limiters - published date from: 20000101- & 316 \\
\hline
\end{tabular}

Figure I Example search strategy.

Note: Example search strategy: CINAHL Plus with Fulltext, MEDLINE, SportDiscus (via EBSCO) 2000 to January II, 2012. 
reminder systems support appointment attendance. We therefore drew on a variety of models that have been developed to understand behavior in relation to medical adherence. Included models related to use of reminders to promote clinical outcomes, ${ }^{21}$ health care utilization theory; ${ }^{22}$ the theory of planned behavior; ${ }^{23}$ the trans-theoretical model $;{ }^{24}$ self-determination theory $;{ }^{25}$ protection motivation theory; ${ }^{26}$ rationale choice theory; ${ }^{27}$ and complexity theory. ${ }^{28}$ Our conceptual framework was developed through an iterative process involving examination of the various theories and discussions about context, mechanisms, and outcomes that were important to explain how reminder systems work to promote attendance, for whom, and in what circumstances. The framework consisted of six broad factors that could potentially influence the effectiveness of the reminder or whether patients would attend, cancel or reschedule their appointment, namely: the reminder-patient interaction, reminder accessibility, health care settings, wider social factors, cancellation and rebooking systems, and patient attributes. This framework was then used to support data extraction.

\section{Review 2}

Our SR of effectiveness investigated the impact of reminder systems on improvements in attendance, cancellations, and rescheduling of appointments. The questions addressed in this were: 1) how effective are reminder systems at reducing non-attendance at appointments and increasing cancellation/ rescheduling of appointments? and 2) which types of reminder systems are most effective in improving the uptake of health service appointments? We used standardized methods to select, quality assess, extract and synthesize the findings of SRs and RCTs. ${ }^{29}$ The Critical Appraisal Skills Program appraisal tool for RCTs was used to quality assess those RCTs not already assessed in pre-existing SRs. ${ }^{30}$ The quality of the included SRs was assessed against the criteria used by the Centre for Reviews and Dissemination when evaluating reviews for inclusion in the Database of Abstracts of Reviews of Effects. ${ }^{31}$ We used these quality assessments to moderate our interpretation of the review findings, not to exclude the papers. ${ }^{32}$

\section{Review 3}

Our evidence synthesis aimed to explore the differential effectiveness of reminder systems for particular population sub-groups; to identify contexts and mechanisms which influence the effectiveness of different reminder systems for particular population sub-groups; and identify any disadvantages which should be considered when introducing reminder systems for specific populations. The data extraction framework used the six elements of the conceptual framework. In accordance with realist principles, not all potentially relevant papers identified from the screening contributed to the synthesis. ${ }^{33}$ All RCTs investigating reminder systems and all reviews (systematic and otherwise) about reminder systems and appointment systems were prioritized for full extraction of contextual and explanatory variables. Whereas RCTs were required to meet minimum quality standards in order to be included in the effectiveness SR, the studies excluded from this SR still had the potential to contribute to the evidence synthesis informed by realist principles. In many cases findings from such studies contributed to the evidence base regarding the mechanisms and contexts that shape the operation of reminder systems in real world settings. Examination of the trial evidence was followed by exploration of qualitative, mixed-methods and nonRCT quantitative studies about reminders and appointments for Europe, America, Canada, Australia, and New Zealand. Thematic analysis was used to examine the evidence available for each section of the framework. Subsequently a narrative synthesis was developed that sought to explain the context and mechanisms influencing how reminders support attendance, cancellation, and rebooking.

\section{Results}

The PRISMA (Preferred Reporting Items for Systematic Reviews and Meta-Analyses) flowchart (Figure 2) shows the numbers of included papers for review 2 and 3. Preliminary database searches yielded 638 unique papers; a further 139 were identified from subsequent searches. Following the screening stages, 466 potentially relevant papers were identified. Eleven SRs met the inclusion criteria for review 2 (Table 1). ${ }^{16-18,34-41}$ These SRs either examined a single technology, eg, an SR of short message service (SMS) reminder systems, ${ }^{17}$ or explored the role of information technologies along a patient care pathway, one of which might be appointment reminder systems. ${ }^{41}$ The quality of included reviews was variable (Table 2). The five Cochrane reviews had been scrutinized against the highest quality standards. ${ }^{16,18,34,36,40}$ Four reviews passed the Centre for Reviews and Dissemination SR quality threshold..$^{17,35,39,41}$ Two reviews did not pass the minimum standard for SRs. ${ }^{37,38}$

Of the 31 RCTs that met our inclusion criteria for review ${ }^{2,4,42-72}$ only ten were uniquely identified by our review. The included RCTs related to the use of systems to remind patients to attend a health-related appointment that had already been scheduled (Table 3 ). The majority of 


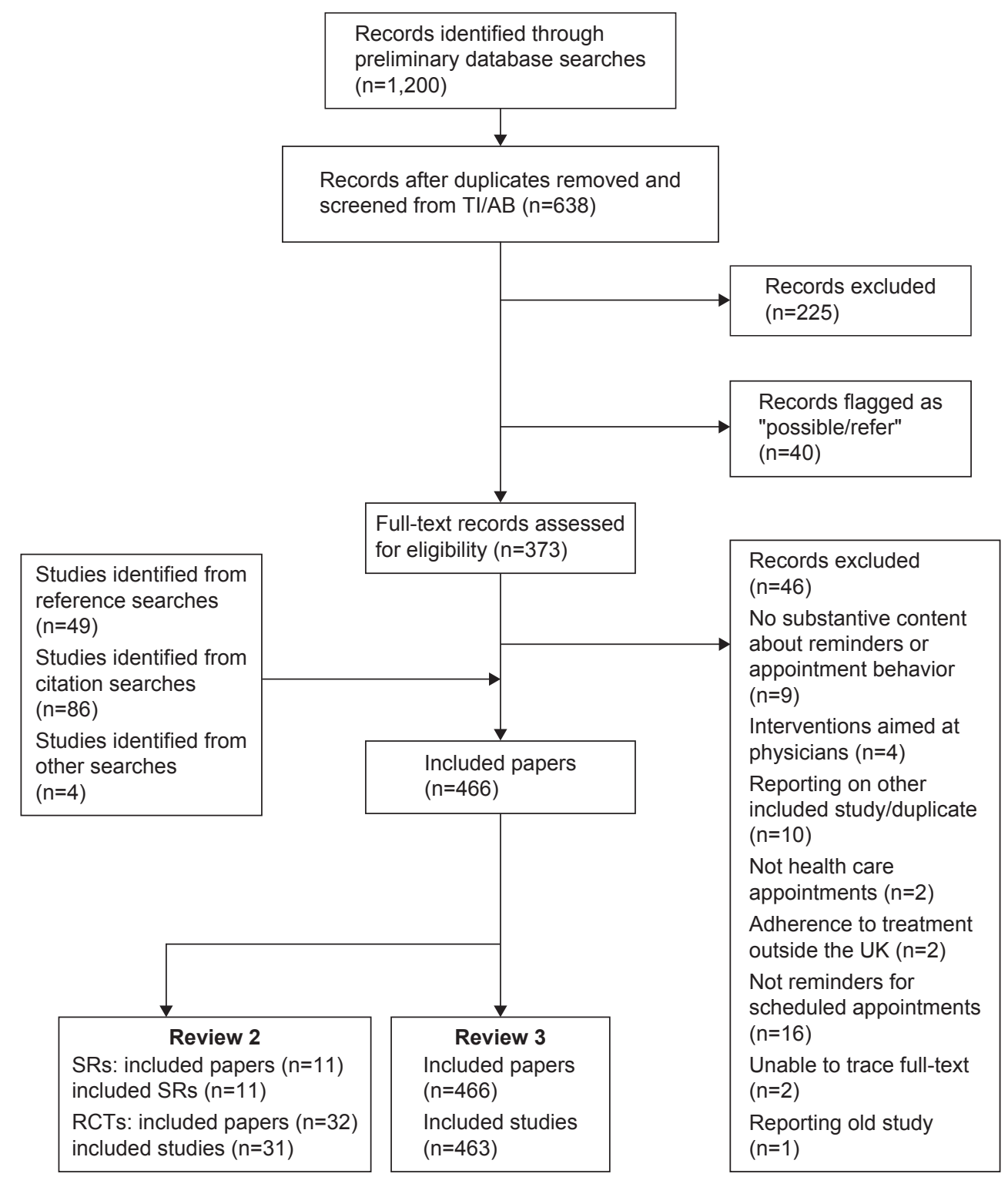

Figure 2 PRISMA flowchart for review 2 and 3.

Abbreviations: PRISMA, Preferred Reporting Items for Systematic Reviews and Meta-Analyses; SRs, systematic reviews; RCTs, randomized controlled trials; TI, titles; AB, abstracts.

Table I Reminder technologies covered by each review

\begin{tabular}{|c|c|c|c|c|c|c|c|}
\hline Study & Letter & $\begin{array}{l}\text { Manual } \\
\text { telephone }\end{array}$ & $\begin{array}{l}\text { Automated } \\
\text { telephone }\end{array}$ & Mobile/SMS & $\begin{array}{l}\text { Voice } \\
\text { messaging }\end{array}$ & Email & Other \\
\hline Atherton et al ${ }^{18}$ & & & & & & $\checkmark$ & \\
\hline Car et $\mathrm{al}^{34}$ & & & & $\checkmark$ & & & \\
\hline Free et $\mathrm{al}^{35}$ & & & & $\checkmark$ & $\checkmark$ & & \\
\hline Glynn et $\mathrm{al}^{36}$ & $\checkmark$ & $\checkmark$ & & $\checkmark$ & & & \\
\hline Guy et al ${ }^{17}$ & & & & $\checkmark$ & & & \\
\hline Hasvold and Wootton ${ }^{37}$ & & $\checkmark$ & $\checkmark$ & $\checkmark$ & & & \\
\hline Henderson ${ }^{38}$ & $\checkmark$ & $\checkmark$ & $\checkmark$ & & & & \\
\hline Jacobson Vann and Szilagyi ${ }^{16}$ & $\checkmark$ & $\checkmark$ & & & & & \\
\hline Krishna et $\mathrm{a}^{39}$ & & & & $\checkmark$ & & & \\
\hline Reda and Makhoul ${ }^{40}$ & $\checkmark$ & $\checkmark$ & $\checkmark$ & $\checkmark$ & & $\checkmark$ & Personal visit \\
\hline Stubbs et $\mathrm{al}^{41}$ & $\checkmark$ & $\checkmark$ & $\checkmark$ & $\checkmark$ & & $\checkmark$ & $\begin{array}{l}\text { Open access } \\
\text { scheduling }\end{array}$ \\
\hline
\end{tabular}

Abbreviation: SMS, short message service. 


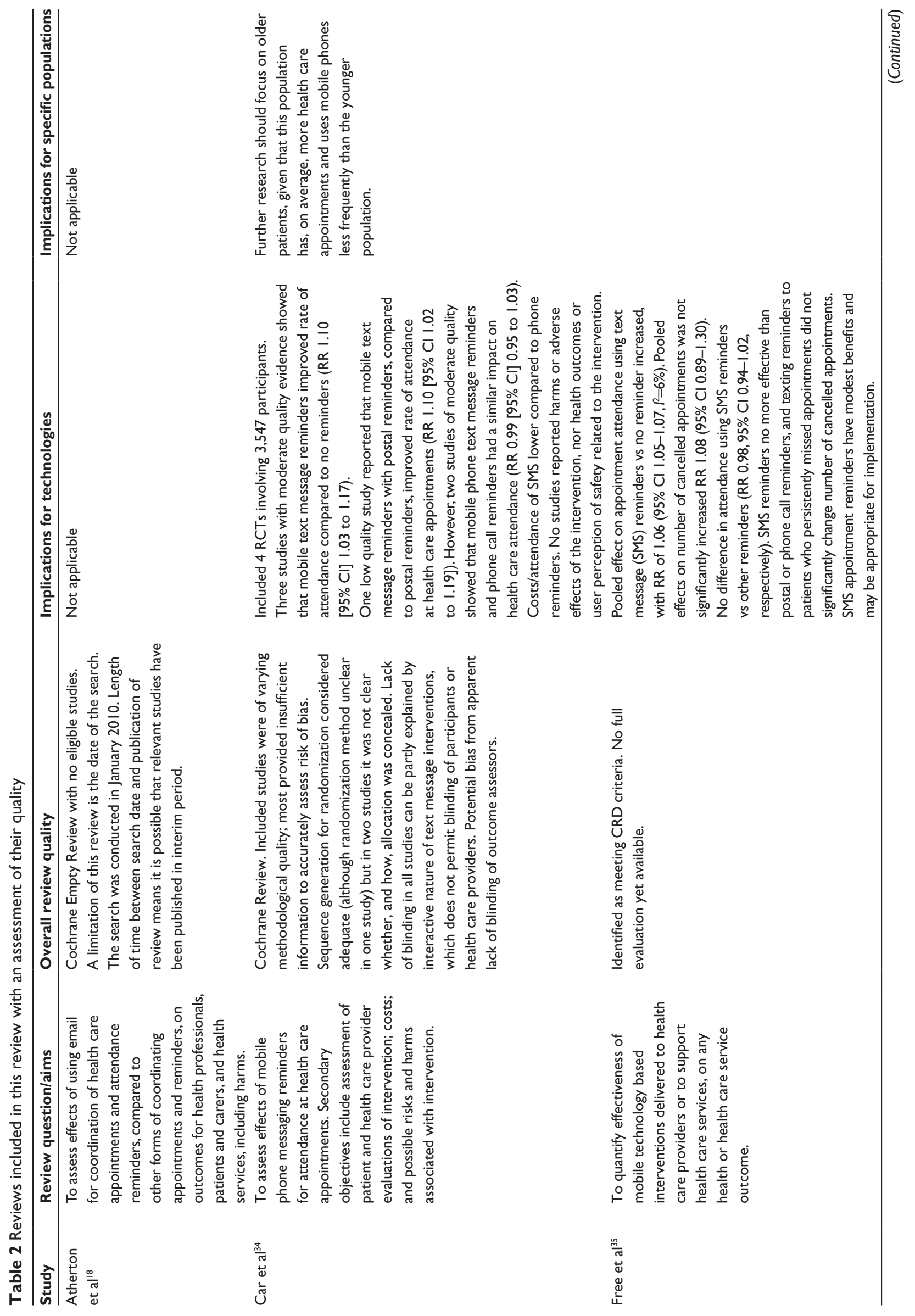




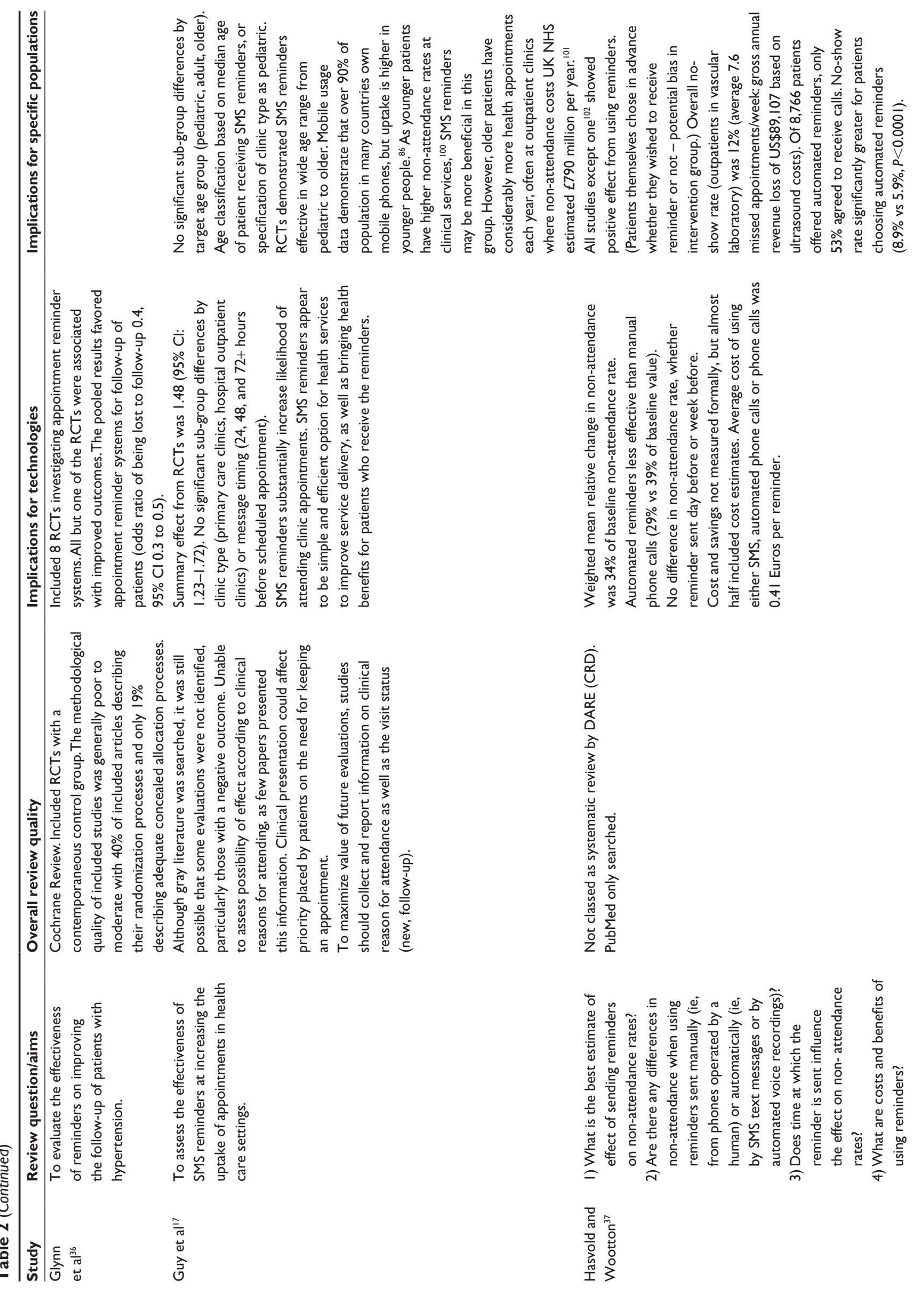




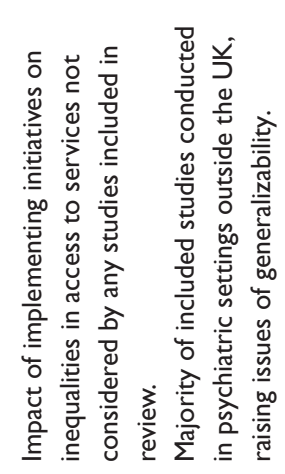

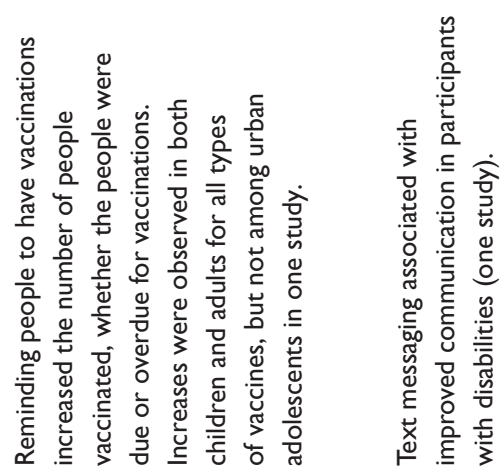

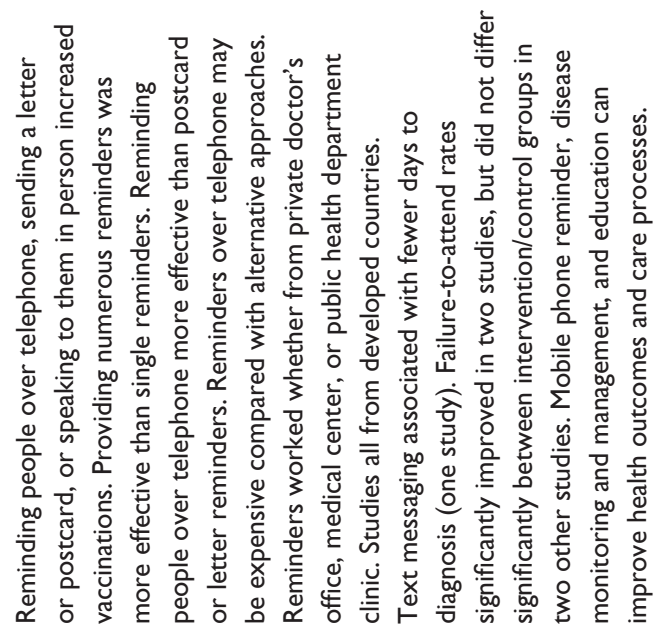

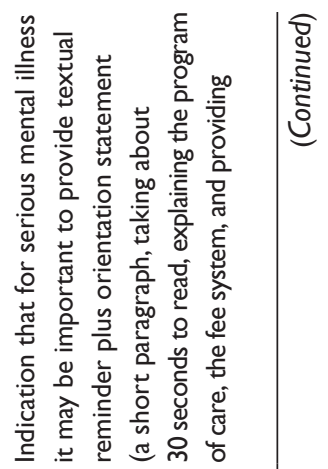

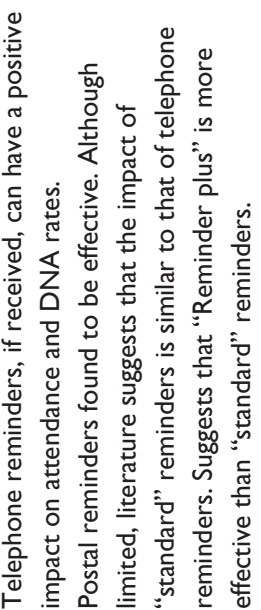
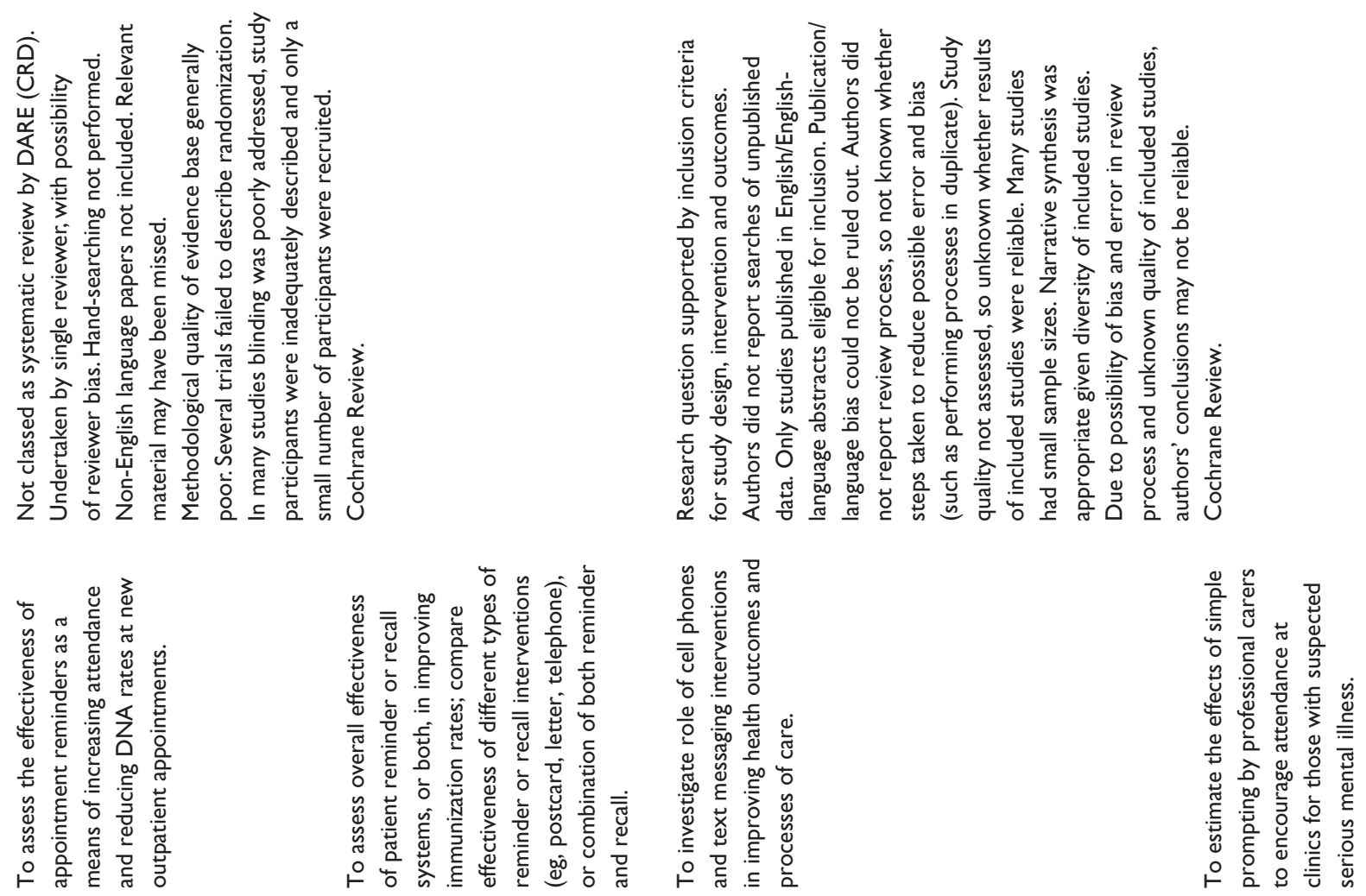

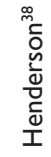

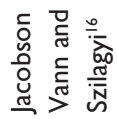

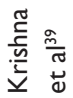

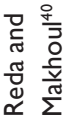




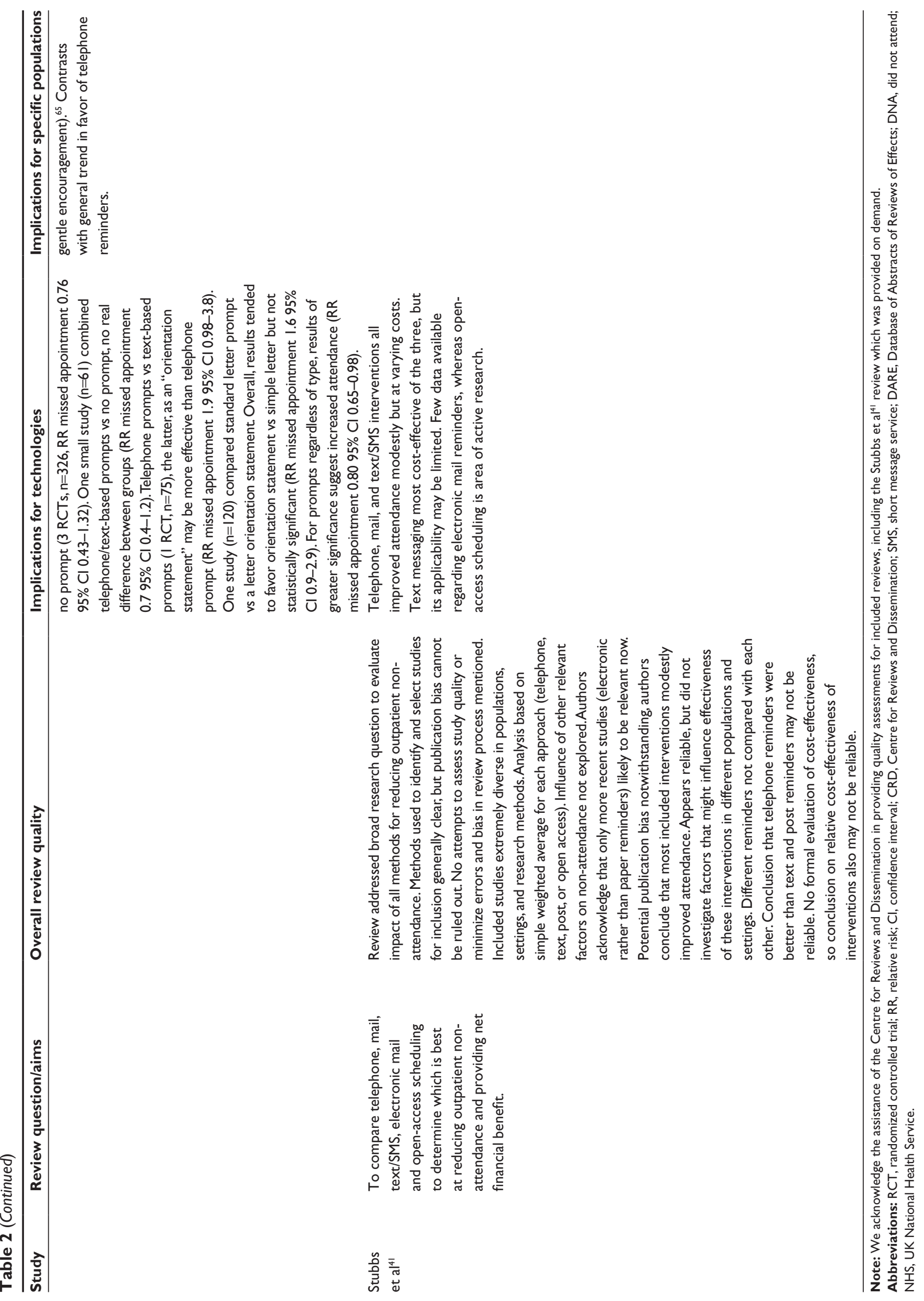




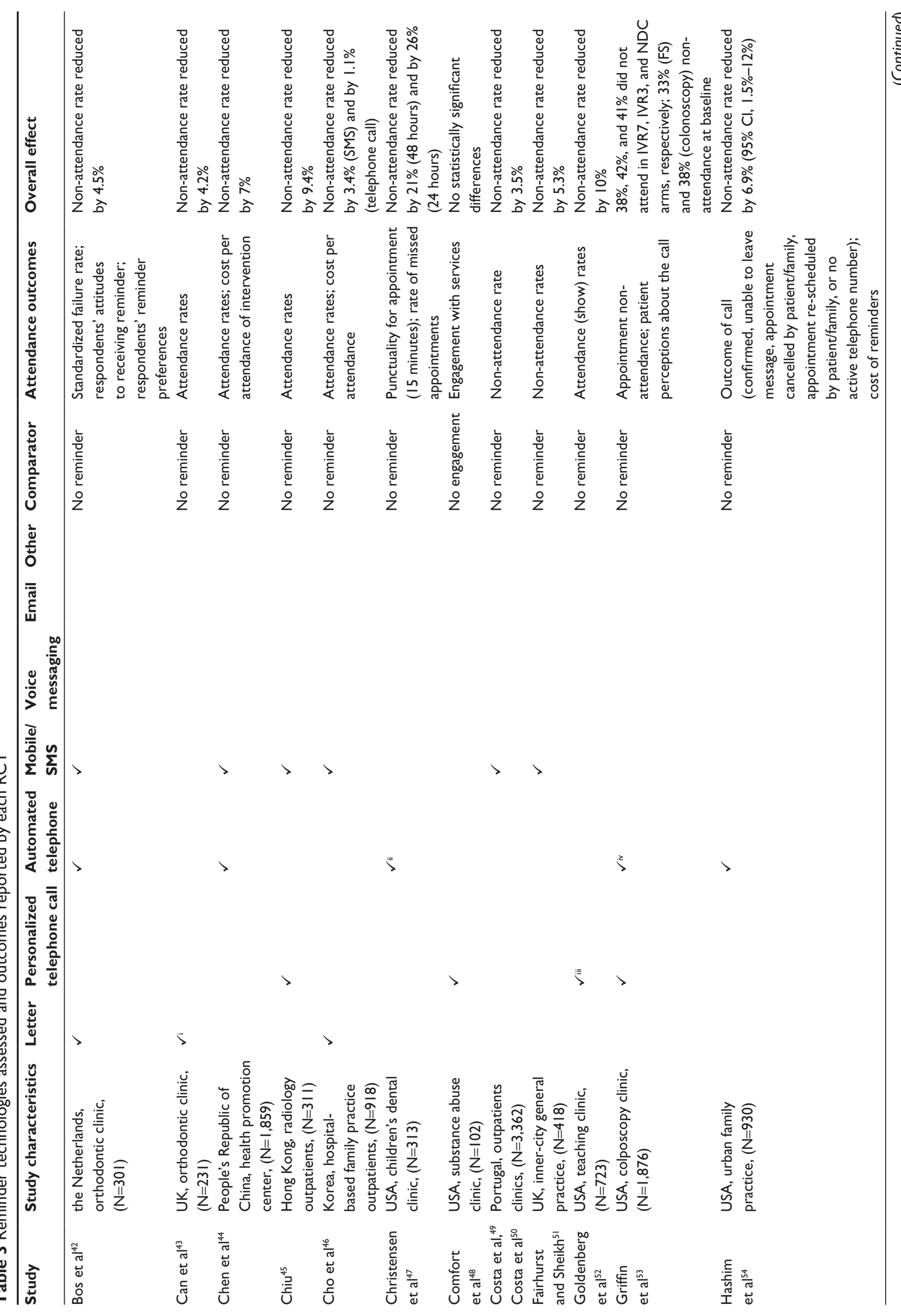




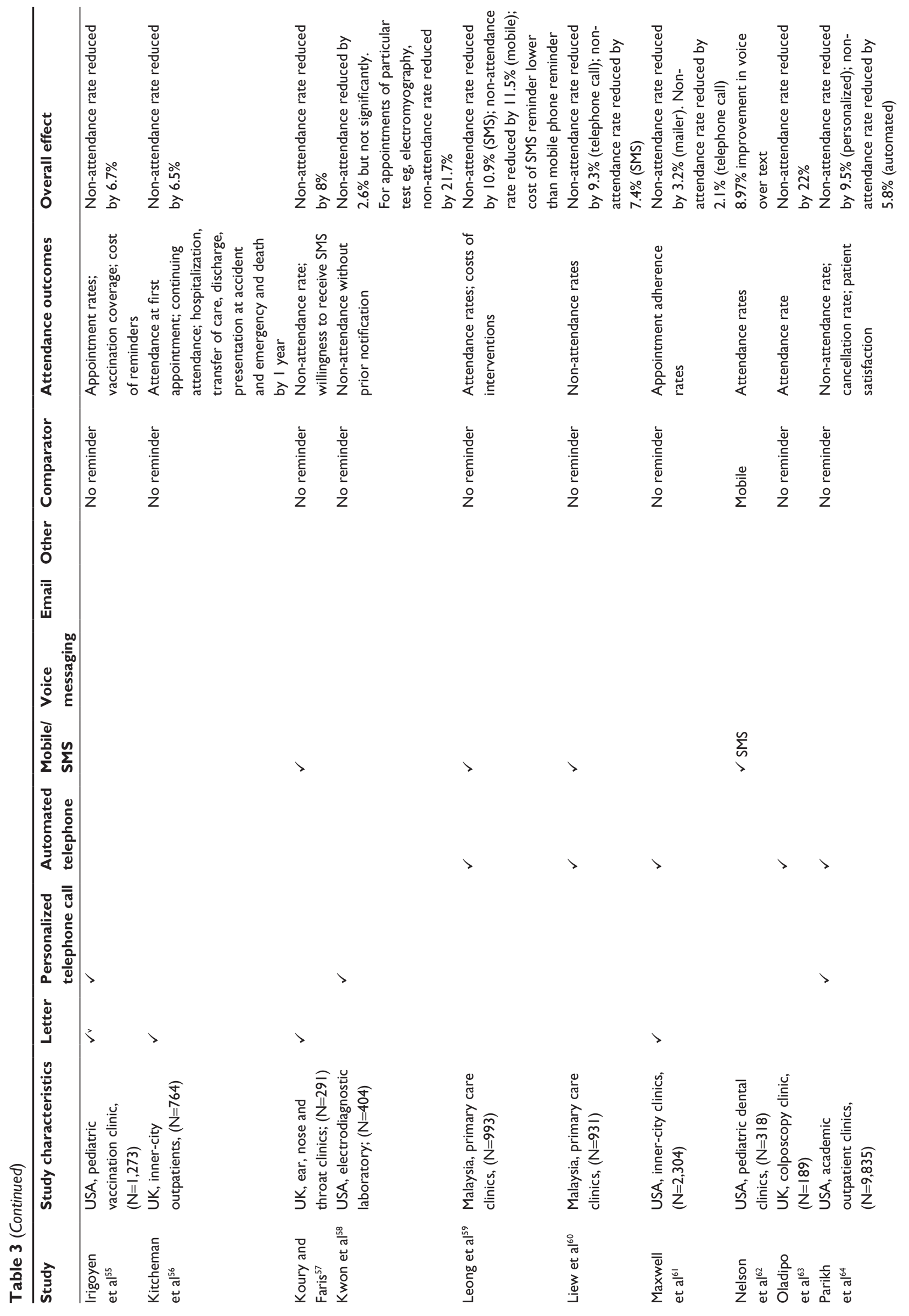



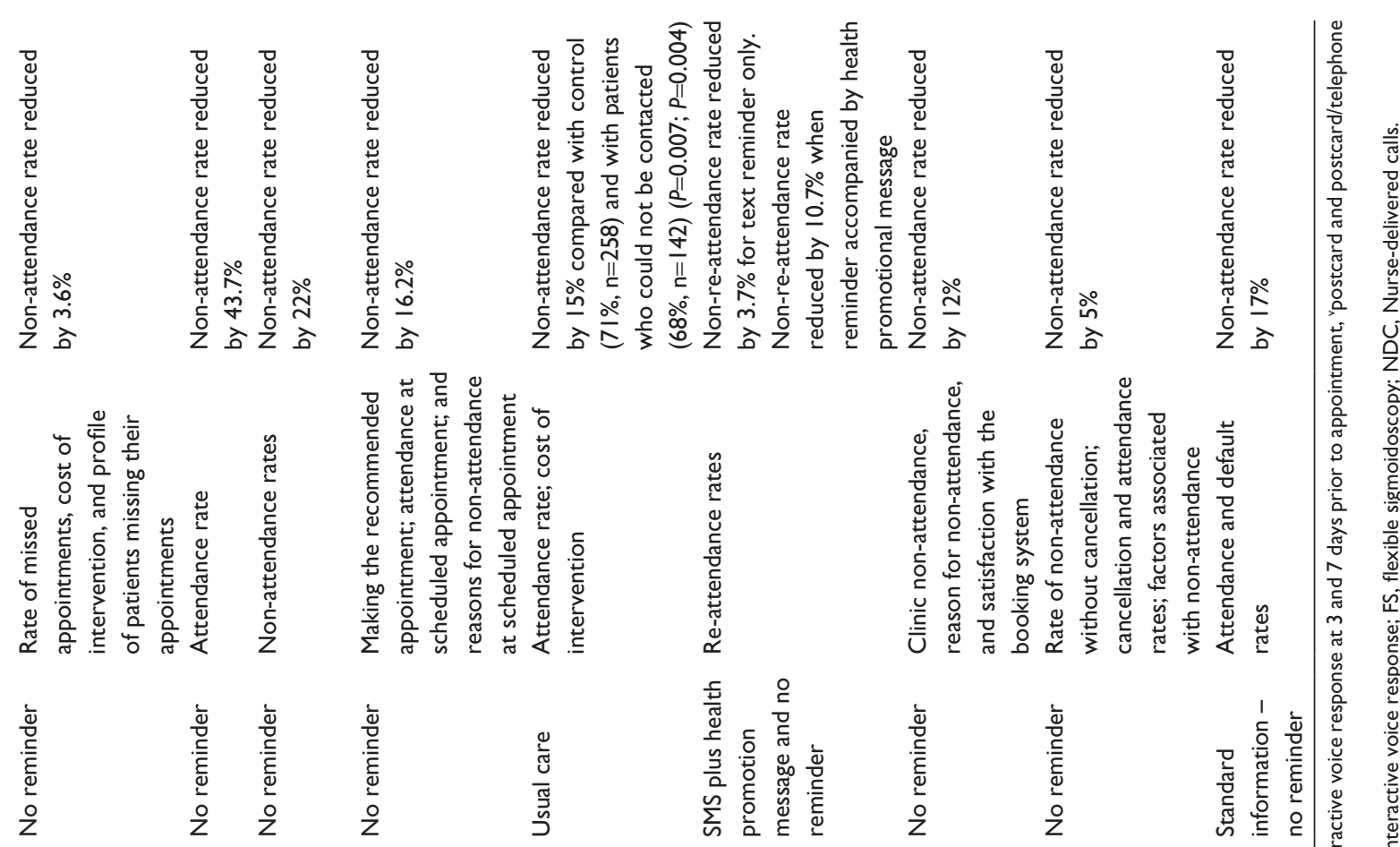
the included RCTs examined either automated telephone reminders $(15 / 31)$ or SMS texting services $(12 / 31)$. Seven RCTs examined personalized telephone calls and 9/31 studies examined postal (letter/postcard) reminders. In most studies the comparator was no intervention. The principal functions of the various reminder systems were reminder only, reminder requiring confirmation, reminder plus orientation or reminder plus supporting clinical information. A variety of attendance related outcomes were measured. These included attendance, cancellation, rescheduling, and patient satisfaction. A judgement of the quality of the uniquely identified RCTs is shown in Table 4.

\section{Reminders increase attendance at appointments}

There was consistent evidence that reminder systems improve appointment attendance across a range of health care settings and patient population sub-groups. Only one of the 31 RCTs did not show a significant reduction in non-attendance. ${ }^{48}$ "Simple reminders", which provide details of date, time, and location of appointments, were most frequently investigated. "Reminder plus", which provides additional information (eg, orientation information, health information, etc) over and above date, time, and location of the appointment, was less commonly investigated. Both were effective at reducing non-attendance.

There was consistent, strong evidence from SRs ${ }^{16,34,35,37,41}$ and $\mathrm{RCTs}^{32,65}$ that simple reminders are effective at increasing attendance at appointments compared with no reminder. In SRs, the pooled effects of simple reminders on appointment attendance vs no reminder indicated significant increases in attendance, with relative risks ranging between $1.06-1.10 .^{34,35}$ One SR reported a weighted mean relative change of $34 \%$ from the baseline non-attendance rate. ${ }^{37}$ In RCTs the difference in attendance between subjects who received reminders and those who did not ranged from 5\% in an Australian physiotherapy clinic to $44 \%$ in an Indian dental preventive care clinic. ${ }^{4,66}$ There was strong evidence from SRs ${ }^{16,34,35}$ and $\mathrm{RCTs}^{42,65}$ that there is no differential effectiveness between different reminder technologies, eg, SMS reminders, phone call reminders or other reminders.

There was weak, but consistent evidence from five studies that "Reminder plus" is more effective than simple reminders at reducing non-attendance. Examples of "Reminder plus" interventions include SMS notification of appointment with a health promotional message or postal reminders with additional information about medical procedures and the importance of follow-up. ${ }^{70,72}$ A Cochrane Review ${ }^{40}$ of

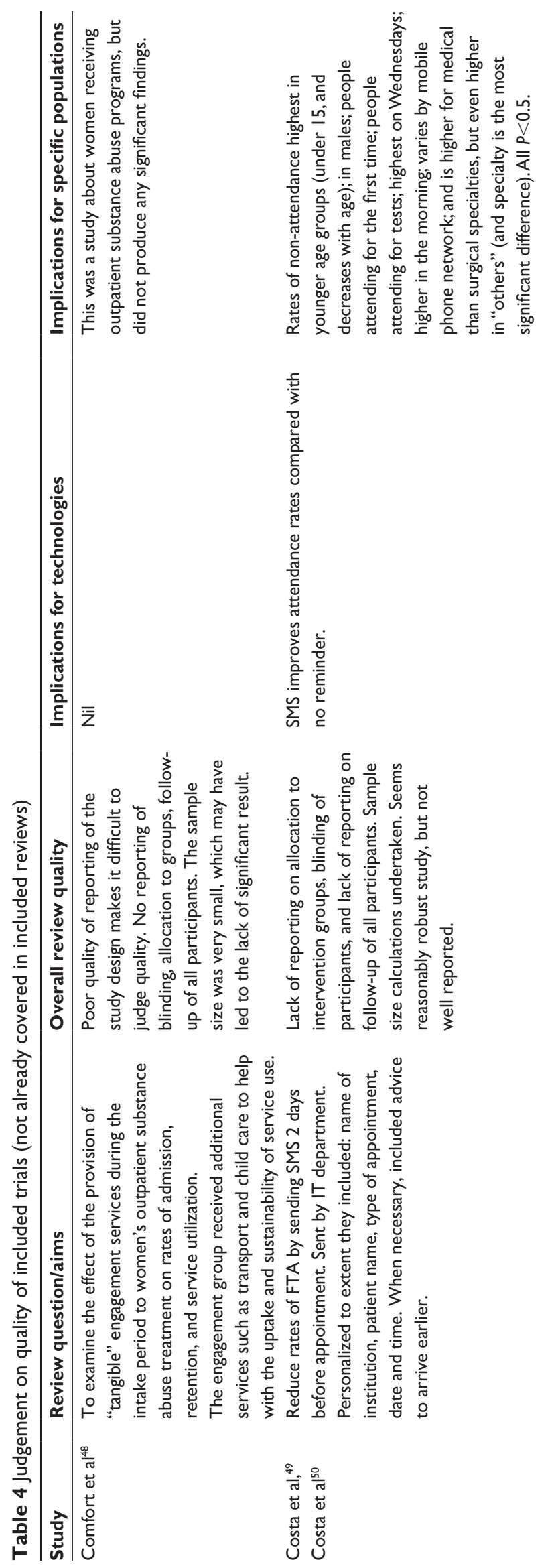




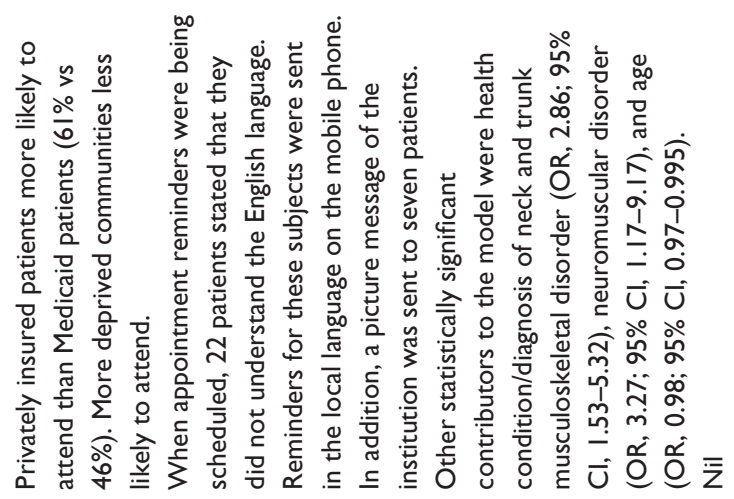
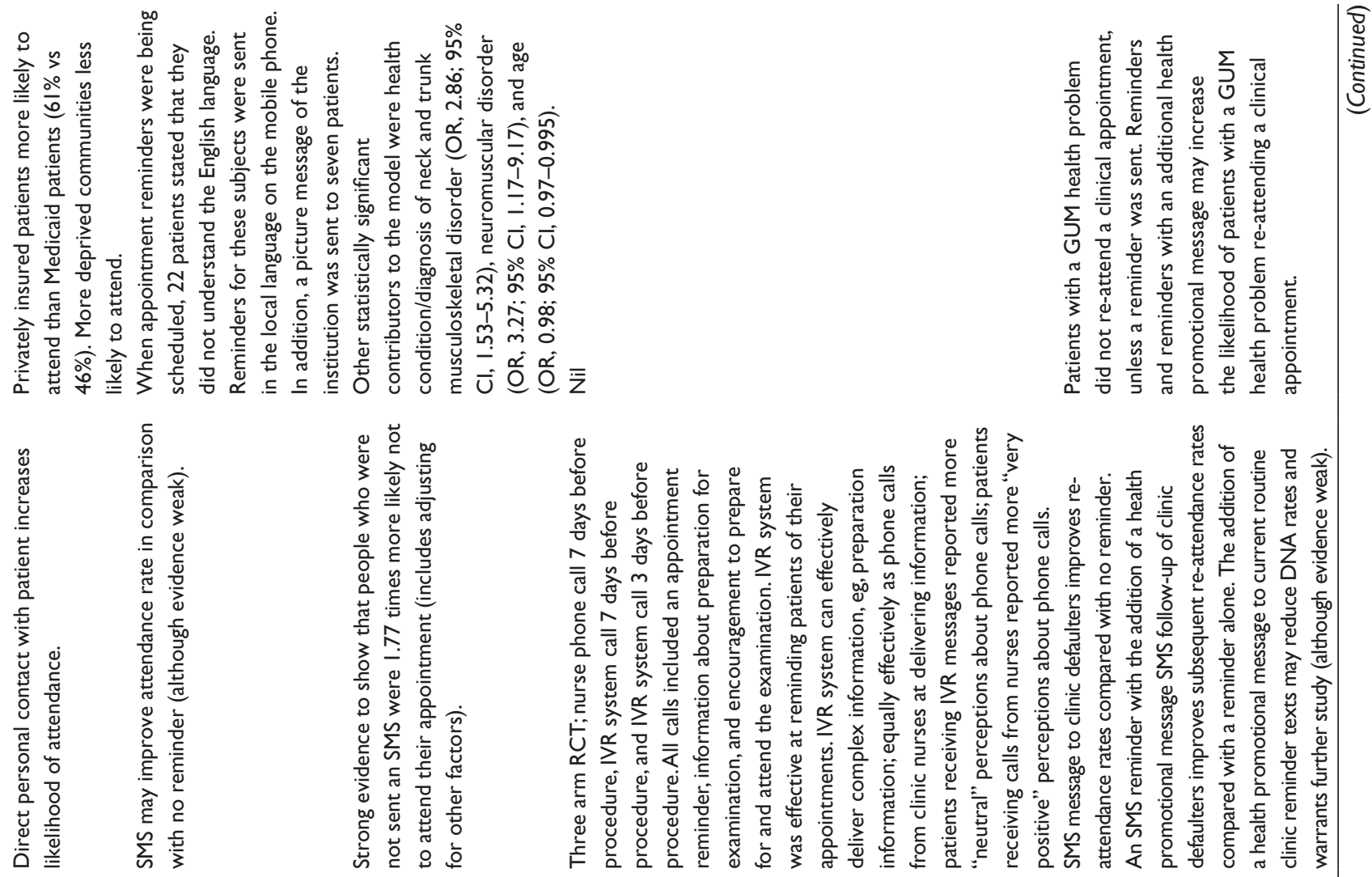

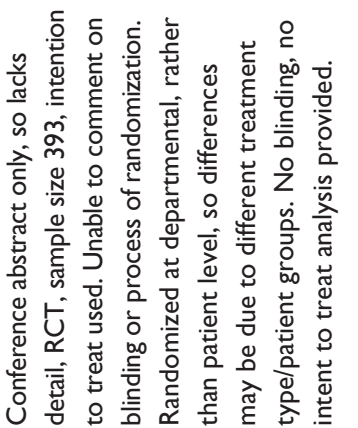
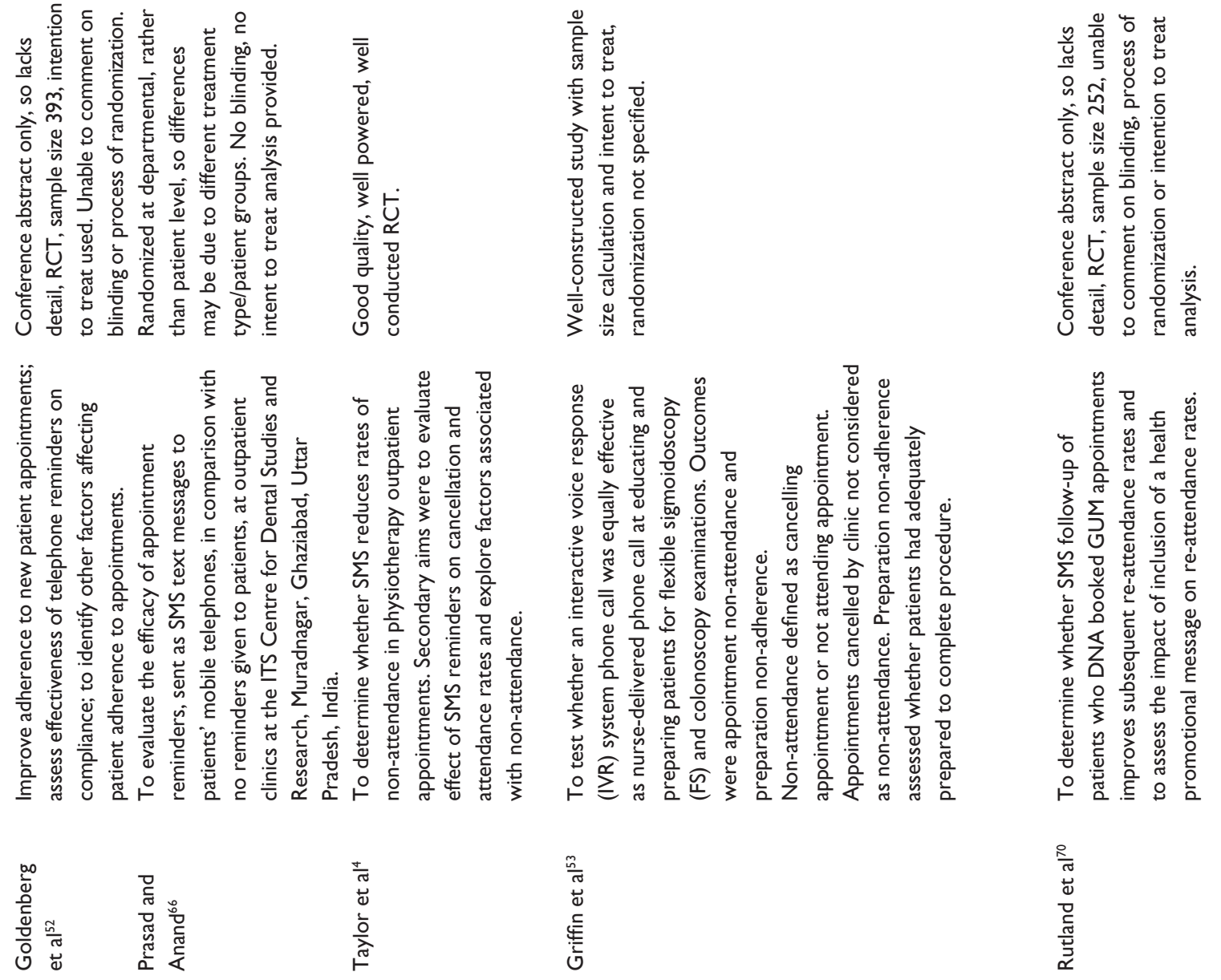

$\frac{0}{\pi}$
$\frac{0}{0}$
$\frac{0}{c}$
$\frac{\pi}{4}$
$\frac{1}{2}$ 


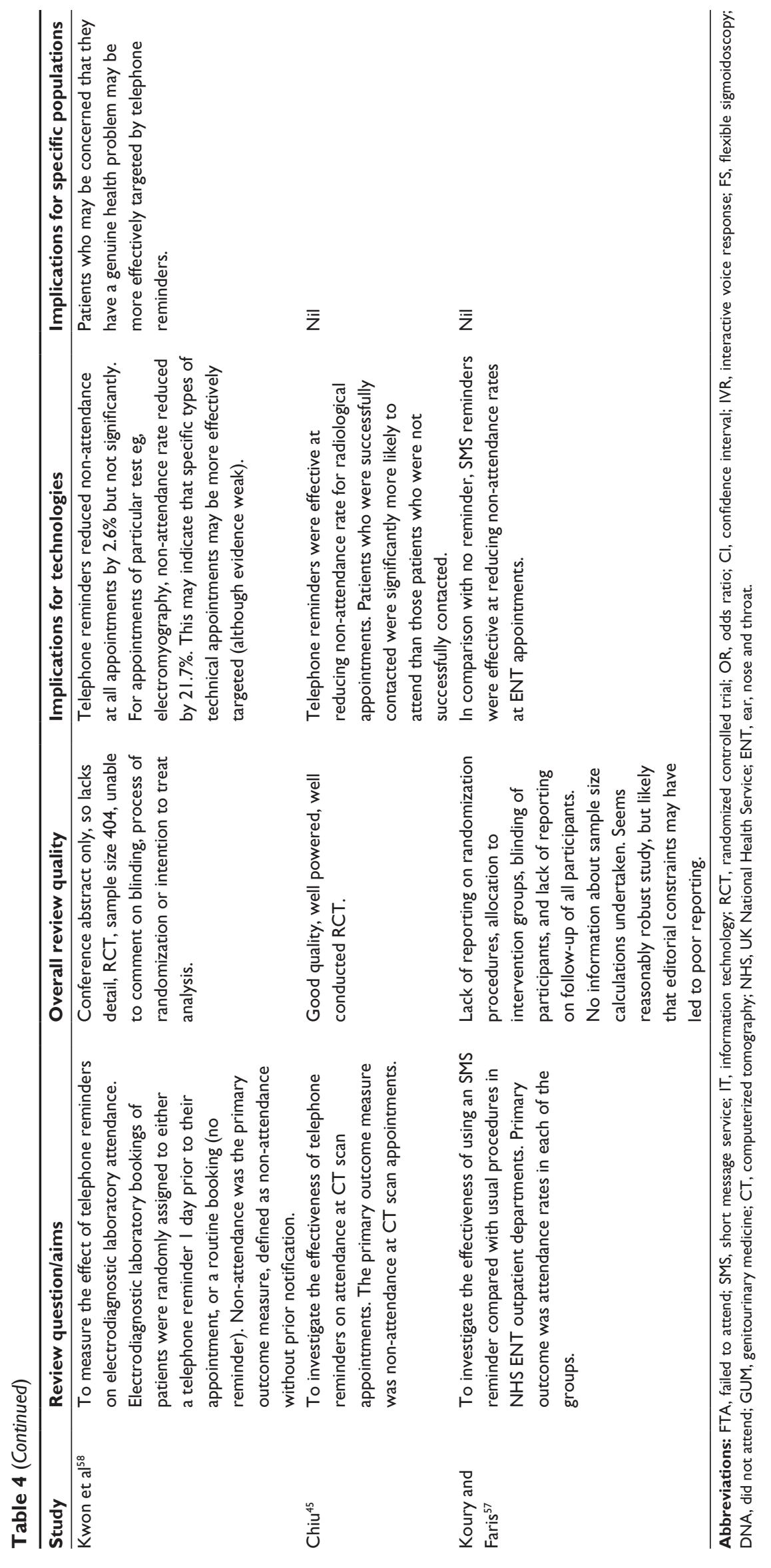


the effects of reminders on clinic attendance for those with suspected serious mental illness, identified one small study favoring a letter with an orientation statement (ie, a short paragraph, taking about 30 seconds to read, explaining the program of care, the fee system, and providing gentle encouragement) over a simple letter prompting attendance. ${ }^{73}$ A second SR to assess the effect of reminder systems on non-attendance rates at new outpatient appointments, found limited evidence in three studies, that "Reminder plus" was more effective than simple reminders. ${ }^{38}$ In these studies, the reminders threatened sanctions for non-attendance, offered rewards for attendance or provided orientation information about the clinic.

\section{Reminders promote cancellation/ reallocation of appointments}

There is evidence from three RCTs that personal phone reminders significantly increase patient cancellation and rescheduling rates. ${ }^{54,64,67}$ Patients who received a telephone reminder were more likely to cancel or reschedule their appointment (17\%-26\%) compared with a control group who had received no reminder $(8 \%-12 \%) .{ }^{54,67,74}$ Clinics were then able to re-allocate between $27 \%$ to $40 \%$ of the cancelled appointment slots. ${ }^{54,65,74}$ Telephone reminders carry the inherent advantage that patients who are unable to attend can cancel and/or reschedule their appointment at the time of their contact with staff. ${ }^{67}$ We also found strong evidence that SMS reminders do not increase appointment cancellation or rescheduling, ${ }^{75-77}$ however this may be because SMS reminders are not conventionally deployed with this in mind.

\section{Reminder systems are not optimally employed}

Our review found sufficient strong consistent evidence to indicate that the performance of reminders, and therefore appointment systems, is suboptimal. Six key areas which lead to sub-optimal reminder effectiveness were identified.

\section{Accuracy of patient records}

Patient contact details are frequently incorrect or out-ofdate. ${ }^{78,79}$ The likelihood of inaccurate patient records corresponds with populations at greater risk of non-attendance, ${ }^{80}$ including less geographically stable communities such as students, young adults or socio-economically deprived groups who may frequently change address or telephone numbers. ${ }^{81}$

\section{Reminders may not be received}

Successful contact rates for telephone reminders are low ranging from $30 \%$ to $60 \%$ in most health care settings. Reasons for non-receipt of telephone reminders are that landline calls are often made during business hours ( 9 am-5 pm), during the working week (Monday to Friday), when it is likely that patients will be out. ${ }^{82}$ In addition, non-receipt may occur because patients do not have a telephone, they do not answer the telephone or the contact number was incorrect. ${ }^{74,83}$ Most telephone reminder systems do not leave messages for reasons of confidentiality.

SMS reminders are reported to have successful contact rates of $97 \%-99 \% .^{79,84}$ Successful contact is assumed when the mobile phone indicates "message sent" being received by the sender. ${ }^{44,59,66}$ However, many patients may either not receive their SMS reminder or may receive and ignore a reminder that was not intended for them due to incorrect data entry on hospital systems. ${ }^{77,79}$ Some clients may not receive their text message until after their scheduled appointment because of delays in delivery of the text or because their phones were switched off, out of battery or out of credit. ${ }^{85}$ One disadvantage of using SMS reminders alone is the different levels of access to a mobile telephone. Mobile phone ownership declines sharply with increasing age, ${ }^{86,87}$ although the total numbers of older people with mobile phone are increasing annually.

\section{Understanding the reminder}

Cognitive ability, literacy level, and language determine patient comprehension of reminders, irrespective of format. These are important considerations for health services serving older populations, travelling communities, inner-city deprived populations, and multilingual communities. The studies included in our review did not explore these factors. Two RCTs explicitly excluded patients who did not speak the official language (English) fluently, those with dementia, or with significant cognitive impairment. ${ }^{68,88}$ Only one RCT used multilingual research assistants to make the reminder phone call. ${ }^{65}$ Reminder systems can cater for different languages. ${ }^{41,66}$

\section{Timing of reminders}

We found strong evidence that the timing of reminders, between 1 and 7 days prior to the scheduled appointment, has no adverse effect on patient attendance behavior. ${ }^{37,89}$ SMS or telephone reminders are typically sent either the day before or on the day of the health care appointment. ${ }^{49,57,63}$ Sending the reminder close to the appointment means that the patient 
may either not have time to act on it or they may receive the reminder after the allotted appointment time. ${ }^{65}$ Sending reminders early allows patients to re-arrange commitments, which may increase the likelihood of a patient attending, cancelling or rescheduling. ${ }^{54,64,67}$

\section{Patient does not cancel or re-schedule the appointment}

There are numerous reasons why patients fail to either cancel or reschedule their appointment. Simple reminders rarely ask patients to cancel appointments, particularly SMS reminders where space for text is limited. ${ }^{46,62}$ Some SMS reminders ask patients to call a telephone number rather than replying to the text. ${ }^{4,57}$ Patients frequently encounter problems accessing health care systems which can thwart their intention to cancel and rebook. ${ }^{86,90}$ Problems include difficulties accessing central booking lines, including the phone being engaged, having to wait a long time to speak to someone or the call being disconnected with no option to wait or leave a message. ${ }^{91,92}$ In some cases, patients were warned by others of the difficulties of accessing a central booking line, which deterred them from making contact. ${ }^{86}$ In two studies, patients who failed to attend stated that they had already phoned or written to cancel their appointment, indicating difficulties with cancellation systems or internal hospital communication prevented cancellations being passed on to the relevant clinic. ${ }^{81,86}$

\section{Lack of tailoring to high risk groups}

There was weak evidence that patient age has no impact on reminder effectiveness, suggesting reminder systems can be employed across all age groups. ${ }^{18}$ However, few studies have investigated the differential impact of reminder systems between population sub-groups. There was weak but consistent evidence that deprivation, minority ethnicity, substance abuse, mental health problems, and comorbidities/illness are associated with non-attendance at appointments. ${ }^{93,94}$ There was little evidence of tailoring of reminder systems to meet the needs of these groups of patients.

\section{Discussion}

This review found consistent, strong evidence that all reminder systems are effective at reducing non-attendance at appointments across diverse service contexts and patient populations. There is no clear indication of differential effectiveness between different simple reminder systems. However, there is some evidence that "Reminder plus" interventions can be more effective than simple reminders. Our review of the available evidence suggests that "Reminder plus" may result in higher attendance than simple reminders for first appointments and screening appointments and that for subsequent follow-up appointments simple reminders and "Reminder plus" may produce comparable increases in attendance for most patients most of the time. However, further research employing appropriate comparative designs is needed before firm conclusions can be drawn.

There is also strong consistent evidence that reminders can increase patient cancellation/rebooking rates, however the success may depend to some extent upon the nature and the timing of the reminder. We found only three studies investigating this area of effectiveness, ${ }^{54,64,67}$ therefore further research exploring the effectiveness of reminder systems to promote cancellation/rebooking and rescheduling of appointments is warranted.

Based on the findings presented in this review, the small amount of evidence that some patients find reminders intrusive or confusing is outweighed by the benefits. ${ }^{95}$ The use of reminders appears to be both acceptable and feasible across a range of health care settings, ${ }^{42,65}$ and we therefore propose that all patients should receive a reminder and that all health care services operating outpatient appointment systems should employ reminder systems.

Whilst reminder systems can increase attendance, cancellation, rescheduling and reallocation of appointments, this review identified six key factors which limit the efficiency of both reminder and appointment systems. Reminder systems are often employed with the objective of increasing attendance rates, with limited attention given to cancellation and/or rescheduling of appointments. Full attendance at appointments is unlikely to be achievable; therefore appointment cancellation and rescheduling should be seen as desirable outcomes. Appointment systems can be optimized if patients cancel and reschedule unwanted appointments, allowing health care services to re-allocate the cancelled appointment to a different patient. If appointment and reminder systems are to realize their full potential this will require a whole systems approach to looking at the characteristics of current systems for attendance, cancellation, rescheduling and re-allocation of appointments to other patients. A summary of proposed strategies is outlined in Figure 3 and discussed in greater detail to follow.

\section{Optimization strategies}

Health services, particularly those serving geographically less stable communities, should have robust procedures for maintaining and updating patient records. ${ }^{81}$ 
1) Maintain accurate patient contact details (with alternative contact routes wherever possible).

2) Select reminder technologies that are suitable for the needs of the population; possibly more than one.

3) Where appropriate use "Reminder plus" technologies to overcome common barriers to attendance.

4) Send reminder a minimum of 2-3 days in advance of the appointment.

5) Frame reminders to ask patients to cancel and reschedule unwanted appointments.

6) Employ multiple systems for cancelling appointments which suit the needs of the patients, not the needs of the service eg, automated SMS cancellation, answer-phone, email etc.

7) Have robust rescheduling procedures in place to allow easy rescheduling of appointments for patients, both within and out of normal working hours.

8) Monitor whether any specific groups of patients are being disadvantaged by the chosen reminder systems.

9) Employ personalized or intensive reminder strategies for groups of patients at high risk of non-attendance.

10) Build in administrative time for clinicians to manage tasks which were previously routinely carried out when a patient missed an appointment.

Figure 3 Summary of strategies to optimize reminder systems.

Abbreviation: SMS, short message service.

In many health services it will be relevant to consider the use of both simple reminders and "Reminder plus". Depending on the nature of the information provided, "Reminder plus" may help patients to feel more confident about attending their appointment, particularly for first appointments and screening appointments. ${ }^{56,96}$ Thereafter, the use of simple reminders may be sufficient for increasing attendance at follow-up appointments in most health care settings.

Since the timing of appointment reminders appears to have no appreciable impact on attendance behavior when delivered up to 7 days before an appointment, we propose that reminders should be delivered early enough to allow patients to re-arrange commitments so that they can attend the appointment and receive the care that they need. Alternatively, if unable to attend, patients will have sufficient time to cancel and reschedule their appointments and allow health services to re-allocate and rebook appointments..$^{54,64,67}$ To support and enhance rescheduling it is appropriate to frame reminders to ask patients to cancel and rebook inconvenient appointments. In addition, robust structures, which are easy to navigate and which require minimal effort from the patient, are required to support cancellation. Automated methods of cancellation, eg, SMS messages or email, are perceived by many patients as easier than methods which require direct contact since they offer flexibility to cancel at a time convenient to the patient and reduce the need to provide explanations for cancellation. ${ }^{18,34}$ Following cancellation of appointments, rescheduling of the appointment, if it has not occurred synchronously, also needs to be easy for the patient. For example it may be sensible, in some health care settings, to have central booking lines which are open 24 hours a day.

There is little evidence of tailoring of reminder systems to meet the needs of vulnerable groups of patients who are at high risk of non-attendance; this includes deprived and ethnic groups, substance abusers, and populations with comorbidity and illness. ${ }^{93,94}$ Given the likely coincidence of higher levels of non-attendance and health need, it is in the interests of health services to monitor whether specific groups of patients are being disadvantaged by the chosen reminder systems. Simple reminders and automated reminders may be ignored, overlooked or misunderstood, particularly if patients are experiencing an increase of their health problem. We therefore hypothesize that reminders with direct personal contact might be appropriate in these groups, since the flexibility of information, advice or support which can be offered may help to overcome barriers to attendance or to cancel unwanted appointments. To facilitate attendance in these groups more intensive reminder systems are advocated. Examples of this include sequential reminders which were effective at improving attendance in a Swiss AIDS clinic. ${ }^{65}$ This consisted of: first, a phone call to either landline or mobile; second, an SMS if participants do not answer the phone after three attempts and have a mobile phone; and finally a postal reminder if participants do not answer the phone, have no mobile phone or landline at all. Intensive approaches, such as "stepped reminders" and patient navigators have also been effective at increasing attendance at screening and immunization programs in disadvantaged and vulnerable populations and might also be effective at reengaging similar groups of patients who have dropped out of treatment. ${ }^{36,97-99}$ Such designs, though labor intensive would reach the maximum number of participants and may increase attendance rates and simultaneously have a cost benefit.

An effective reminder and cancellation system will increase the already heavy workload of outpatient clinics. ${ }^{52}$ Clinicians frequently fill missed appointments with alternative activities such as completing dictation, making telephone calls or 
consulting with colleagues. ${ }^{56}$ If building in processes to optimize cancellation and rescheduling, then health services will need also to consider the impact on staff that frequently utilize non-attendance at appointments as an opportunity to catch up on other health care related activities.

\section{Strengths and limitations}

Our approach to this review, which combined an SR with an evidence synthesis informed by realist principles, has numerous strengths, including a structured search protocol requiring thorough searches of electronic databases, reference lists, and citations. As a consequence we believe that we have assembled the widest possible body of relevant knowledge which has relevance across all health care services which use appointment systems. In addition, our review informed by realist principles includes the strong embedding of our findings in the extracted data. This stems from the practical orientation of our review and facilitates the production of implications for practice. There are also limitations to our review. Generally speaking the SR method seeks to provide a precise answer to a tightly focused question. Such reviews are most useful where there is a high degree of homogeneity around the five PICOS elements, namely the Population, Intervention, Comparison, Outcomes, and Study types. A wide range of population types, intervention, comparison, and outcomes is included within the RCTs we identified. However, use of this wider approach offers greater analytical capability in terms of understanding contextual and mechanistic factors that would not have been evident in a more narrowly focused review and increases confidence that the findings have relevance in a wide range of service settings.

\section{Research implications}

We recommend future research activities in three main areas. Firstly, more studies should routinely consider the potential for differential effects of reminder systems between patient groups in order to identify any inequalities and remedies. Secondly, "Reminder plus" systems appear promising but there is a need for further research to understand how they influence attendance behavior. Finally, further research is required to identify strategies to "optimize" reminder systems and compare performance against current approaches.

\section{Conclusion}

In the absence of clear contraindications all health services should use simple reminders or "Reminder plus" for all patients. More intensive reminder alternatives may be relevant for key groups of patients: deprived, ethnic, substance abusers, and those with comorbidities and illness.

There is evidence that reminders are used sub-optimally. To optimize appointment and reminder systems, health services should tailor reminder systems and adopt supportive administrative processes to enhance attendance, cancellation, rescheduling, and reallocation of appointments to other patients.

\section{Acknowledgments}

The TURNUP project was funded by the National Institute for Health Research Health Services and Delivery Research Program (project number 10/2002/49). The views and opinions expressed are those of the authors and do not necessarily reflect those of the HS\&DR program, NIHR, NHS or the Department of Health. This paper or the abstract of this paper has been presented as a platform presentation at the World Congress of Physical Therapy, Singapore in May 2015 and will also be presented as a platform presentation at Physiotherapy UK in October 2015, Liverpool UK. The abstract was published in Physiotherapy Journal: http://www.physiotherapyuk.org.uk/presentation/ appointment-reminder-systems-are-effective-not-optimalresults-systematic-review-and. The actual paper, however, has never been published.

\section{Disclosure}

The authors report no conflicts of interest in this work.

\section{References}

1. Ulmer T, Troxler C. The economic cost of missed appointments and the open access system; 2006. Available from: http://citeseerx.ist.psu. edu/viewdoc/download?doi=10.1.1.513.1864\&rep=rep1\&type=pdf. Accessed December 20, 2013.

2. Mandirola $\mathrm{H}$, Guillen S, Laguzzi P. IT technologies to reduce the rate of missed appointments in the outpatients. 24th International Conference of the European Federation for Medical Informatics Quality of Life through Quality of Information; 2012. Available from: http://person. hst.aau.dk/ska/mie2012/CD/Interface_MIE2012/MIE_2012_Content/ MIE_2012_Content/SCP/295_CD_SC_Poster_ID_121.pdf. Accessed October 20, 2015.

3. Nour El-Din MM, Al-Shakhs FN, Al-Oudah SS. Missed appointments at a university hospital in eastern Saudi Arabia: Magnitude and association factors. J Egypt Public Health Assoc. 2008;83(5-6): 415-433.

4. Taylor NF, Bottrell J, Lawler K, et al. Mobile telephone short message service reminders can reduce nonattendance in physical therapy outpatient clinics: A randomized controlled trial. Arch Phys Med Rehabil. 2012;93(1):21-26.

5. Quarterly hospital activity - published data. Department of Health; 2012. Available from: http://transparency.dh.gov.uk/?p=19701. Accessed October 20, 2015.

6. Martin C, Perfect T, Mantle G. Non-attendance in primary care: The views of patients and practices on its causes, impact and solutions. Fam Pract. 2005;22(6):638-643. 
7. Beecham L. Missed GP appointments cost NHS money. BMJ. 1999; 319(7209):536.

8. Kennard J. UK: Missed hospital appointments cost NHS $£ 600$ million [updated 2009]. Available from: http://www.digitaljournal.com/ article/277529. Accessed October 20, 2015.

9. Gucciardi E. A systematic review of attrition from diabetes education services: Strategies to improve attrition and retention research. Can J Diabetes. 2008;32(1):53-65.

10. Murdock A, Rodgers C, Lindsay H, Tham TC. Why do patients not keep their appointments?: Prospective study in a gastroenterology outpatient clinic. J Roy Soc Med. 2002;95(6):284-286.

11. Weinger K, McMurrich SJ, Yi JP, Lin S, Rodriguez M. Psychological characteristics of frequent short-notice cancellers of diabetes medical and education appointments. Diabetes Care. 2005;28(7): 1791-1793.

12. Taylor S, Ellis I, Gallagher M. Patient satisfaction with a new physiotherapy telephone service for back pain patients. Physiotherapy. 2002; 88(11):645-657.

13. Lloyd J, Dillon D, Hariharan K. Outpatient clinics. Down the line. Health Serv J. 2003;113(5837):22-23.

14. Karter AJ, Parker MM, Moffet HH, et al. Missed appointments and poor glycemic control: An opportunity to identify high-risk diabetic patients. Med Care. 2004;42(2):110-115.

15. Ambrose J, Beech B. Tackling non-attendance for outpatient appointments. Ment Health Pract. 2006;9(5):22-25.

16. Jacobson Vann JC, Szilagyi P. Patient reminder and recall systems to improve immunization rates. Cochrane Database of Syst Rev. 2005; (3):CD003941

17. Guy R, Hocking J, Wand H, et al. How effective are short message service reminders at increasing clinic attendance? A meta-analysis and systematic review. Health Serv Res. 2012;47(2):614-632.

18. Atherton H, Sawmynaden P, Meyer B, Car J. Email for the coordination of healthcare appointments and attendance reminders. Cochrane Database of Syst Rev. 2012;8:CD007981.

19. Wong G, Greenhalgh T, Westhorp G, Buckingham J, Pawson R. RAMESES publication standards: realist syntheses. BMC Med. 2013; 11(1):21.

20. McLean S, Gee M, Booth A, et al. Targeting the Use of Reminders and Notifications for Uptake by Populations (TURNUP): a systematic review and evidence synthesis. Health Services and Delivery Research 2014;2(34).

21. Coomes CM, Lewis MA, Uhrig JD, et al. Beyond reminders: A conceptual framework for using short message service to promote prevention and improve healthcare quality and clinical outcomes for people living with HIV. AIDS Care. 2012;24(3):348-357.

22. Phillips KA, Morrison KR, Andersen R, Aday LA. Understanding the context of healthcare utilization: Assessing environmental and providerrelated variables in the behavioral model of utilization. Health Serv Res. 1998;33(3 Pt 1):571-596.

23. Ajzen I. From intentions to actions: A theory of planned behavior. In: Kuhl J, Beckmann J, editors. Action-control: From cognition to behavior. 1st ed. Heidelberg: Springer; 1985:11-39.

24. Prochaska JO, Norcross JC, DiClemente CC. Changing for good: The revolutionary program that explains the six stages of change and teaches you how to free yourself from bad habits. New York: W. Morrow; 1994.

25. Deci EL, Ryan RM. An overview of self-determination theory. In: Ryan RM, editor. The Oxford Handbook of Human Motivation. USA Oxford University Press; 2012:85-107.

26. Rogers RW. A protection motivation theory of fear appeals and attitude change. J Psychol. 1975;91:93-94.

27. Rothman AJ, Salovey P. Shaping perceptions to motivate healthy behaviour: The role of message framing. Psychol Bull. 1997;121(1) 3-19.

28. Cooper HC, Geyer R. What can complexity do for diabetes management? linking theory to practice. J Eval Clin Pract. 2009;15(4) 761-765.
29. Centre for Reviews and Dissemination. Systematic reviews: CRD's guidance for undertaking reviews in health care. York: CRD, University of York; 2009.

30. Critical Appraisal Skills Programme (CASP). CASP randomized controlled trial checklist. CASP; 2013. Available from: http://media.wix. com/ugd/dded87_40b9ff0bf53840478331915a8ed8b2fb.pdf. Accessed October 21, 2015.

31. Centre for Reviews and Dissemination. The database of abstracts of reviews and effects (DARE). Effectiveness Matters; 2002. Available from: https://www.york.ac.uk/media/crd/em62.pdf. Accessed October 21, 2015.

32. Conn VS, Rantz MJ. Research methods: Managing primary study quality in meta-analyses. Res Nurs Health. 2003;26(4):322-333.

33. Pawson R. Method mix, technical hex, and theory fix. In: Bergman MM, editor. Advances in mixed methods research: Theories and applications. Los Angeles, CA: Sage; 2008:120-137.

34. Car J, Gurol-Urganci I, de Jongh T, Vodopivec-Jamsek V, Atun R. Mobile phone messaging reminders for attendance at healthcare appointments. Cochrane Database of Syst Rev. 2012;7:CD007458.

35. Free C, Phillips G, Watson L, et al. The effectiveness of mobile-health technologies to improve health care service delivery processes: a systematic review and meta-analysis. PLoS Med. 2013;10(1):e1001363.

36. Glynn LG, Murphy AW, Smith SM, Schroeder K, Fahey T. Interventions used to improve control of blood pressure in patients with hypertension. Cochrane Database Syst Rev. 2010;(3):CD005182.

37. Hasvold PE, Wootton R. Use of telephone and SMS reminders to improve attendance at hospital appointments: a systematic review. J Telemed Telecare. 2011;17(7):358-364.

38. Henderson R. Encouraging attendance at outpatient appointments: can we do more? Scott Med J. 2008;53(1):9-12.

39. Krishna S, Boren SA, Balas EA. Healthcare via cell phones: a systematic review. Telemed J E Health. 2009;15(3):231-240.

40. Reda S, Makhoul S. Prompts to encourage appointment attendance for people with serious mental illness. Cochrane Database Syst Rev. 2001;(2):CD002085.

41. Stubbs ND, Geraci SA, Stephenson PL, Jones DB, Sanders S. Methods to reduce outpatient non-attendance. Am J Med Sci. 2012;344(3): 211-219.

42. Bos A, Hoogstraten J, Prahl-Andersen B. Failed appointments in an orthodontic clinic. Am J Orthod Dentofacial Orthop. 2005;127(3): 355-357.

43. Can S, Macfarlane T, O'Brien KD. The use of postal reminders to reduce non-attendance at an orthodontic clinic: a randomised controlled trial. Br Dent J. 2003;195(4):199-201.

44. Chen Z, Fang L, Chen L, Dai H. Comparison of an SMS text messaging and phone reminder to improve attendance at a health promotion center: a randomized controlled trial. J Zhejiang Univ Sci B. 2008;9(1): 34-38.

45. Chiu S. The effect of telephone reminders on the attendance for CT scan: A randomized control trial. HKU Theses Online (HKUTO); 2005.

46. Cho SJ, Kim YS, Shin HC, et al. A randomized controlled trial of SMS text messaging versus postal reminder to improve attendance after lipid lowering therapy in primary care. Korean Journal of Family Medicine. 2010;31(4):284-293.

47. Christensen AA, Lugo RA, Yamashiro DK. The effect of confirmation calls on appointment-keeping behavior of patients in a children's hospital dental clinic. Pediatr Dent. 2001;23(6):495-498.

48. Comfort M, Loverro J, Kaltenbach K. A search for strategies to engage women in substance abuse treatment. Soc Work Health Care. 2000; 31(4):59-70

49. Costa J, Lima M, Sousa D, et al. Impact of Appointment Reminders via Short Message Service in a District Hospital. Faculdade de Medicina, Universidade do Porto: Department of Biostatistics and Medical Informatics; 2010. Report No.: Introdução à Medicina 2006/2007. Available from: http://medicina.med.up.pt/im/trabalhos06_07/sites/ Turma4/minhaweb/images/IntroMed\%20Annual\%20Assignment\%20\%20Class\%204\%20-\%20Paper.pdf. Accessed December 1, 2015. 
50. Costa J, Lima M, Sousa D, et al. Impact of appointment reminders via short message service in a district hospital RID A-2756-2009. 2008:564. Available from: http://slideplayer.com/slide/5101460/. Accessed December 10, 2015.

51. Fairhurst K, Sheikh A. Texting appointment reminders to repeated non-attenders in primary care: randomised controlled study. Qual Saf Health Care. 2008;17(5):373-376.

52. Goldenberg S, DeLuca J, Sacajiu G, et al. Effect of reminder calls on new patient appointment adherence. J Gen Intern Med. 2003;18:131-132.

53. Griffin JM, Hulbert EM, Vernon SW, et al. Improving endoscopy completion: Effectiveness of an interactive voice response system. Am J Manag Care. 2011;17(3):199-208.

54. Hashim MJ, Franks P, Fiscella K. Effectiveness of telephone reminders in improving rate of appointments kept at an outpatient clinic: a randomized controlled trial. J Am Board Fam Pract. 2001;14(3):193-196.

55. Irigoyen MM, Findley S, Earle B, Stambaugh K, Vaughan R. Impact of appointment reminders on vaccination coverage at an urban clinic. Pediatrics. 2000;106(4 Suppl):919-923.

56. Kitcheman J, Adams CE, Pervaiz A, et al. Does an encouraging letter encourage attendance at psychiatric out-patient clinics? The leeds PROMPTS randomized study. Psychol Med. 2008;38(5):717-723.

57. Koury E, Faris C. Mobile phones and clinic appointments: The start of a beautiful new friendship? Br J Healthc Comput Inf Manage. 2005; 22(8):18-20.

58. Kwon SB, Hong SS, Kang SY, et al. Telephone call reminders and attendance in an electromyography laboratory. J Neurol. 2010;257(Suppl 1): S185.

59. Leong KC, Chen WS, Leong KW, et al. The use of text messaging to improve attendance in primary care: a randomized controlled trial. Fam Pract. 2006;23(6):699-705.

60. Liew SM, Tong SF, Lee VK, et al. Text messaging reminders to reduce non-attendance in chronic disease follow-up: a clinical trial. $\mathrm{Br} J \mathrm{Gen}$ Pract. 2009;59(569):916-920.

61. Maxwell S, Maljanian R, Horowitz S, et al. Effectiveness of reminder systems on appointment adherence rates. J Health Care Poor Underserved. 2001;12(4):504-514.

62. Nelson TM, Berg JH, Bell JF, Leggott PJ, Seminario AL. Assessing the effectiveness of text messages as appointment reminders in a pediatric dental setting. J Am Dent Assoc. 2011;142(4):397-405.

63. Oladipo A, Ogden S, Pugh S. Preclinic appointment telephone contact: An effective intervention for colposcopy clinic nonattendance. $J$ Low Genit Tract Dis. 2007;11(1):35-38.

64. Parikh A, Gupta K, Wilson AC, et al. The effectiveness of outpatient appointment reminder systems in reducing no-show rates. Am J Med. 2010;123(6):542-548.

65. Perron NJ, Dao MD, Kossovsky MP, et al. Reduction of missed appointments at an urban primary care clinic: a randomised controlled study. BMC Fam Pract. 2010;11:79.

66. Prasad S, Anand R. Use of mobile telephone short message service as a reminder: The effect on patient attendance. Int Dent J. 2012;62(1): 21-26.

67. Reti S. Improving outpatient department efficiency: A randomized controlled trial comparing hospital and general-practice telephone reminders. N Z Med J. 2003;116(1175):U458-U458.

68. Ritchie PD, Jenkins M, Cameron PA. A telephone call reminder to improve outpatient attendance in patients referred from the emergency department: A randomised controlled trial. Aust $N Z$ J Med. 2000;30(5):585-592.

69. Roberts NJ, Partridge MR. Telephone consultations in secondary care. Respir Med. 2007;101(8):1665-1669.

70. Rutland E, Roe H, Weaver A. O11 health promotional messages in short message service (SMS) follow-up of GU medicine clinic defaulters; a tool to improve subsequent attendance rates? Sex Transm Infect. 2012;88(Suppl 1):A4-A5.

71. Sawyer SM, Zalan A, Bond LM. Telephone reminders improve adolescent clinic attendance: A randomized controlled trial. J Paediatr Child Health. 2002;38(1):79-83.
72. Tomlinson A, Kyrgiou M, Paraskevaidis E, Kitchener H, Martin-Hirsch P. Does improving communication and information for women increase attendance at colposcopy in an inner city clinic? A randomised controlled trial. Eur J Gynaecol Oncol. 2004;25(4):445-448.

73. Swenson TR, Pekarik G. Interventions for reducing missed initial appointments at a community mental health center. Community Ment Health J. 1988;24(3):205-218.

74. Blankenstein R. Failed appointments - do telephone reminders always work? Clinical Governance. 2003;8(3):208-212.

75. Nair VR, Butt A, Baguley S. Text reminders are reducing non-attendance rate significantly. Int J STD AIDS. 2008;19(6):429.

76. Foley J, O'Neill M. Use of mobile telephone short message service (SMS) as a reminder: The effect on patient attendance. Eur Arch Paediatr Dent. 2009;10(1):15-18.

77. Koshy E, Car J, Majeed A. Effectiveness of mobile-phone short message service (SMS) reminders for ophthalmology outpatient appointments: observational study. BMC Ophthalmol. 2008;8:9.

78. Perry JG. A preliminary investigation into the effect of the use of the Short Message Service (SMS) on patient attendance at an NHS Dental Access Centre in Scotland. Prim Dent Care. 2011;18(4):145-149.

79. Downer SR, Meara JG, Da Costa AC, Sethuraman K. SMS text messaging improves outpatient attendance. Aust Health Rev. 2006;30(3): 389-396.

80. Sharp DJ, Hamilton W. Non-attendance at general practices and outpatient clinics. BMJ. 2001;323(7321):1081-1082.

81. Corfield L, Schizas A, Noorani A, Williams A. Non-attendance at the colorectal clinic: a prospective audit. Ann R Coll Surg Engl. 2008;90(5): 377-380.

82. Clough BA, Casey LM. Technological adjuncts to increase adherence to therapy: a review. Clin Psychol Rev. 2011;31(5):697-710.

83. Mariotto A. Reminder calls help waiting-lists' management and fairness. Internet J Healthc Adm. 2004;2(1):6.

84. Geraghty M, Glynn F, Amin M, Kinsella J. Patient mobile telephone 'text' reminder: A novel way to reduce non-attendance at the ENT out-patient clinic. J Laryngol Otol. 2008;122(3):296-298.

85. Judson G, Blain D, Taranaki A. Text reminders in an outpatient A\&D service: one way to reduce non-attendance. In: Adamson S, Schroder RN, Sheridan J, editors. New Zealand Addiction Treatment Research Monograph. Research Proceedings from the Cutting Edge Conference; 2010. 2012:29-31.

86. Snow R, Fulop N. Understanding issues associated with attending a young adult diabetes clinic: a case study. Diabetic Med. 2012;29(2): 257-259.

87. Milne RG, Horne M, Torsney B. SMS reminders in the UK national health service: An evaluation of its impact on "no-shows" at hospital out-patient clinics. Health Care Manage Rev. 2006;31(2):130-136.

88. Zanjani F, Bush H, Oslin D. Telephone-based psychiatric referralcare management intervention health outcomes. Telemed J E Health. 2010;16(5):543-550.

89. Glynn LG, Murphy AW, Smith SM, Schroeder K, Fahey T. Selfmonitoring and other non-pharmacological interventions to improve the management of hypertension in primary care: a systematic review. Br J Gen Pract. 2010;60(581):e476-e488.

90. Woods MD, Kirk MD, Agarwal MS, et al. Vulnerable groups and access to health care: a critical interpretive review. National Coordinating Centre for NHS Service Delivery and Organization R \& D; 2005. Available from: http://mighealth.net/uk/images/8/84/Dix1.pdf. Accessed October 21, 2015

91. Hussain-Gambles M. Missed appointments in primary care: questionnaire and focus group study of health professionals. Br J Gen Pract. 2004;54(499):108-113.

92. George A, Rubin G. Non-attendance in general practice: a systematic review and its implications for access to primary health care. Fam Pract. 2003;20(2):178-184.

93. Alexandre NM, Nordin M, Hiebert R, et al. Predictors of compliance with short-term treatment among patients with back pain. Rev Panam Salud Pública. 2002;12(2):86-95. 
94. Coodin S, Staley D, Cortens B, Desrochers R, McLandress S. Patient factors associated with missed appointments in persons with schizophrenia. Can J Psychiatry. 2004;49(2):145-148.

95. Sanghara H, Kravariti E, Jakobsen H. Using short message services in mental health services: assessing feasibility. Mental Health Review Journal. 2010;15(2):28-33.

96. Booth PG, Bennett HE. Factors associated with attendance for first appointments at an alcohol clinic and the effects of telephone prompting. Journal of Substance Use. 2004;9(6):269-279.

97. Hambidge SJ, Phibbs SL, Chandramouli V, Fairclough D, Steiner JF. A stepped intervention increases well-child care and immunization rates in a disadvantaged population. Pediatrics. 2009;124(2):455-464.

98. Battaglia TA, Kronman A, Beaver K, Freund KM. Improving follow-up to abnormal breast cancer screening in an urban population: A patient navigation intervention. Cancer Prevention Research. 2010;3(12).
99. Percac-Lima S, Grant RW, Green AR, et al. A culturally tailored navigator program for colorectal cancer screening in a community health center: a randomized, controlled trial. J Gen Intern Med. 2009;24(2): 211-217.

100. Neal RD, Hussain-Gambles M, Allgar VL, Lawlor DA, Dempsey O. Reasons for and consequences of missed appointments in general practice in the UK: questionnaire survey and prospective review of medical records. BMC Fam Pract. 2005;6:47.

101. Sharp DJ, Hamilton W. Non-attendance at general practices and outpatient clinics. BMJ. 2001;323:1081-1082.

102. Satiani B, Miller S, Patel D. No-show rates in the vascular laboratory: analysis and possible solutions. J Vasc Interv Radiol. 2009;20:87-91.

\section{Publish your work in this journal}

Patient Preference and Adherence is an international, peer-reviewed, open access journal that focuses on the growing importance of patient preference and adherence throughout the therapeutic continuum. Patient satisfaction, acceptability, quality of life, compliance, persistence and their role in developing new therapeutic modalities and compounds to optimize clinical outcomes for existing disease states are major areas of interest for the journal. This journal has been accepted for indexing on PubMed Central. The manuscript management system is completely online and includes a very quick and fair peer-review system, which is all easy to use. Visit http://www. dovepress.com/testimonials.php to read real quotes from published authors.

Submit your manuscript here: http://www.dovepress.com/patient-preference-and-adherence-journal 